- Đối với lãnh đạo Bệnh viện cần quan tâm và đối xử bình đẳng với điều dưỡng, tạo nguồn kinh phí chi trả tiền lương và phụ cấp tương xứng với cống hiến của điều dưỡng do bệnh viện tự chi hoàn toàn và phân công công việc phù hợp với vị trí làm việc của từng điều dưỡng.

- Đối với đội ngũ điều dưỡng cần rèn luyện, trau dồi, học tập nâng cao trình độ chuyên mổn, nghiệp vụ, cập nhật kiến thức mới và thực hành tốt y đức.

\section{TÀI LIẸU THAM KHẢO}

1. Alan Tiến (2018), "Thang đo Likert và các bước xây dưng Likert hiểu quả".

2. Báo cáo kết quả khảo sát mức độ hài lòng của nhân viên y tế 2018 của Bệnh viện Đa khoa Trung tâm Tiền Giang.
3. Báo cáo tổng kết năm 2019 của Bệnh viện Đa khoa Trung tâm Tiền Giang.

4. Lê Trí Khải (2016), "Sứ hài lòng đối với công viêc của nhân viên y tế cơ sở tỉnh Kon Tum năm 2016".

5. Vũ Xuân Phú (2012), "Thực trạng nguồn nhân lực và một số yếu tố ảnh hưởng đển sự hài lòng với công việc của nhân viên y tế Bệnh viện đa khoa Sóc Sớn, Hà Nôi năm 2011", Tạp chí Ỳ hoc thực hành, 821-5/2012, pp. tr 153-159.

6. Lế Nguyến Đoan Khôi và Đố Hữu Nghi "Các nhân tố ảnh hưởng đến mức độ hài lòng công việc của nhân viên y tế tại Thành Phố Cần thơ năm 2014".

7. Cambridge Dictionary Online (2015), "Cambridge Dictionary Online (2015), job satisfaction. Available from 10/11/2015".

8. Oxford University Press (2015), "Oxford University Press (2015), Principles of Organizational Behaviour 4e: Glossary. Available from .htm, accessed 12/02/2017".

\title{
TÌM HIỂU MộT SỐ ĐĂC ĐIỂM LÂM SÀNG, X-QUANG, CẮT LỚP VI TÍNH CỦA BỆNH NHÂN GÃY KÍN DUPUYTREN ĐƯợC KẾT XƯƠNG BÊN TRONG TẠI BỆNH VIỆN TRUNG ƯƠNG QUÂN ĐộI 108
}

\section{TÓM TẮT}

Muc tiêu: Gãy Dupuytren là môt tổn thương đăc biệt vừng cổ chân, là một tổn thương thường gặp trển lâm sàng. Mục tiêu của nghiên cứu này là tìm hiểu đăc điểm lâm sàng, XQ, CT Scanner của loại gãy này. Đối tượng, phương pháp: Đối tượng nghiên cứu gồm 38 BN gãy kín Dupuytren, được phâu thuật kết xương bên trong từ 9/2015-6/2020 tại Bênh viện TWQĐ 108. Có 22 nam và 16 nữ, tuổi trung bình 46,26 tuổi (2272), trong đó gãy ở chân trái là $23 \mathrm{BN}$, gãy chân phải là 15 BN. Nguyên nhân tổn thương là TNGT gặp ở 20 $\mathrm{BN}$, do TNLĐ gặp ở $2 \mathrm{BN}$, do ngã gặp ở $13 \mathrm{BN}$, do TNTT gặp ở 3 BN. Các BN được chụp XQ thẳng, nghiêng. Chụp CT Scanner được thực hiện ở 20 BN gãy 3 mắt cá. Các đăc điểm lâm sàng, XQ, CT Scanner được thu thập và phân tích. Kết quả: 20 BN gãy 3 mắt cá, 17 BN gãy 2 mắt cá, $1 \mathrm{BN}$ gãy mắt cá ngoài đơn thuần. Có 2 BN gãy loại I, 8 BN gãy loại II, 4 BN gãy loại III, 2 BN gãy loai IV theo phân loại gãy mắt cá sau của Bartonicek. Có 23 BN gãy kiểu Weber B và 13 BN kiểu Weber $C$. Tất cả BN đều có hình ảnh tổn thương mộng chày mác và bán trật xương sên ra ngoài. Cơ chế tổn thương chính là xoay ngoài (33/38 BN). Chẩn đoán gãy mắt cá sau dựa vào đường gãy chéo vát trên phim $X Q$ tư thế nghiêng của $20 \mathrm{BN}$ và hình ảnh đường viền kép ở $4 \mathrm{BN}$ và hình núi mờ ở 16 $\mathrm{BN}$ trên phim $\mathrm{X}$ quang thẳng. $\mathrm{CT}$ Scan cho thấy kích

${ }^{1}$ Bệnh viện TUQQĐ 108

Chịu trách nhiệm chính: Nguyễn Văn Lượng

Email: luongnv@gmail.com

Ngày nhận bài: 8/8/2021

Ngày phản biên khoa hoc: 10/9/2021

Ngày duyệt bài: 30/9/2021
Nguyễn Văn Lượng ${ }^{1}$, Nguyễn Điện Thành Hiệp ${ }^{1}$

thước, vị trí gãy, hình ảnh lún, chèn mảnh gãy nhỏ, di lệch lớn của mảnh gãy mắt cá sau ngay trên diện khớp. Kết luân: Gãy Dupuytren với các tổn thương đặc trưng: Gãy mắt cá ngoài, gãy mắt cá trong hoặc đứt dây chằng Delta; doãng mộng chày mác, có hoặc không có kèm gãy mắt cá sau. Cơ chế tổn thương chủ yếu là xoay ngoài cổ chân. XQ có thể chẩn đoán được gãy Dupuytren, tuy nhiên XQ có một số hạn chế trong chẩn đoán tổn thương gãy mắt cá sau, vì vậy nên chụp CT Scans để đánh giá gãy mắt cá sau. mắt cá

Tư khóa: Gãy Dupuytren, gãy 2 mắt cá, gãy 3

\section{SUMMARY \\ RESEARCH FEATURES OF CLINICAL SIGNS RADIOGRAPH AND COMPUTED TOMOGRAPHY (CT) SCANS OF PATIENTS WITH CLOSED DUPUYTREN FRACTURE TREATED WITH OPEN REDUCTION AND INTERNAL FIXATION IN 108 CENTRAL MILITARY HOSPITAL}

Objective: Dupuytren fracture is a special type of ankle's injury which are popular in clinic. The aim of this study is to investigate the clinical features and radiograph features and computed tomography (CT) scans of these fracture. Patients and methods: The data of 38 patients with closed Dupuytren fracture from September 2015 to June 2020, who were treated with open reduction and internal fixation in 108 Central Military Hospital were retrospectively analyzed. There were 22 males and 16 females, the average age was 46.26 years (range, 22 to 72 years), the fractures occurred on the left side in 23 patients and on the right side in 15 patients. The cause of injuries were traffic accidents in 20 patients, labor accident in 2 
patients, and falling injury in 13 patients, sports injury in 3 patients. All patients underwent A-P and lateral $\mathrm{X}$-ray examinations of the ankle. CT-scan of the ankle was performed in 20 patients of trimalleolar fractures. The features of clinical signs, radiograph and computed tomography (CT) scans were recorded and analyzed. Results: 20 patients had triple trimalleolar fractures. 17 patients had bimalleolar fractures and 1 patient had simple lateral malleolar fracture. There were 2 patients with type I fracture, 8 patients with type II fracture, 4 patients with type III, 2 patients with type IV fracture according to the Bartonicek classification of posterior malleolus fracture. There were 23 patients with type $B$ and 15 patients with type $\mathrm{C}$ according to the Weber classification of malleolus fracture. The syndesmosis injury with lateral translation of the talus was shown in all patients. The common injury mechanism was foot external rotation (33 out of 38 patients). The fracture of the posterior malleolus was diagnosed with oblique fracture in lateral X-ray in 20 of 20 patients had posterior malleolus, with a double density in A-P X-ray in 4 patients, with a light mountain in A-P X-ray in 16 patients. CT-scan shown impaction, interposed fragments, and significant displacement of posterior malleolus just above the articular surface. Conclusions: Dupuytren fracture is characterized by fractures of the lateral malleolus, fractures of the medial malleolus or rupture of Delta tendon and widen syndesmosis, with or without posterior malleolar fracture. External rotation is the main injury mechanism. This fracture was diagnosed with X-rays but it had some limitations in the diagnosis of posterior malleolar fractures, and $\mathrm{CT}$ examinations should be performed to evaluate the posterior malleolar fracture.

Keywords: Dupuytren fracture, bimalleolar fracure, trimalleolar fracture.

\section{I. ĐĂT VẤN ĐỀ}

Gãy Dupuytren là một dạng gãy xương vùng cổ chân với thương tổn đặc trưng: Gãy mắt cá trong (MCT) hoặc đứt dây chằng Delta; gãy mắt cá ngoài $(\mathrm{MCN})$, doãng mônng chày mác và đứt dây chằng chày mác dưới, xương sên bán trật khớp ra ngoài, nếu có gãy mắt cá sau (MCS) thì kèm theo bán trật khớp xương sên ra sau. Các thương tổn này làm mất sự vững chắc của khớp chày sên - một khớp chịu sức nặng của toàn cơ thể khi đi lại. Nếu xương sên bị trật ra ngoài 1 $\mathrm{mm}$ thì diện tích tiếp xúc với xương sên của khớp chày sên sẽ giảm đi $42 \%$ [1], điêu này sẽ dẫn đến thoái hóa sớm khớp châyy sên. Chẩn đoán các tổn thương trong gãy Dupuytren dựa trên

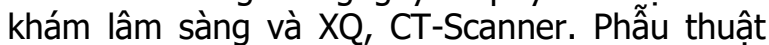
nắn chỉnh mở và kêtt hợp xương bên trong ngày càng phổ biến với mục đích nắn chỉnh phục hồi lại giải phấu và cố định ổ gãy xương, phục hồi vị trí giải phẫu của xương sên, cố định lại khớp châyy mác dưới, giúp bệnh nhân vận động phục hồi chức năng sớm và tránh các di chứng chấn thương. Trên thế giới đã có nhiều công trình nghiên cứu về gãy các mắt cá nói chung và gãy Dupuytren nói riêng [2], [3], [4]... Ở Việt Nam cũng có một số tác giả báo cáo về kết quả điều trị kết xương Dupuytren tuy nhiên chưa có nghiên cứu sâu về lâm sàng và hình ảnh $X$ quang, CT- Scanner của loại gãy này, đặc biệt là khi có gãy mắt cá sau kèm theo. Vì vậy, chúng tôi tiến hành nghiên cứu đề tài: "Nghiên cứu đặc điểm lâm sàng và $X$-quang, cắt lớp vi tính của bênh nhân gãy kín Dupuytren được kết xương bển trong tại Bệnh viện Trung ương Quân đội 108" nhằm mục đích:

- Mô tả đặc điểm lâm sàng và X quang của bênh nhân gãy kín Dupuytren được kêt hợp xương bên trong tại Bênh viện TUQQD 108.

- Dánh giá vai trò của cắt lăp vi tính trong chân đoán gãy Dupuytren.

\section{II. ĐỐl TƯỢNG VÀ PHƯƠNG PHÁP NGHIÊN CỨU}

2.1. Đối tượng nghiên cứu. Gồm $38 \mathrm{BN}$ được chẩn đoán gãy kín Dupuytren được phẫu thuật kết xương bên trong tại khoa Chấn thương chỉnh hình tổng hợp, Bệnh viện Trung ương Quân đội 108, từ 9/2015 đến 6/2020.

Tiêu chuẩn lựa chọn: $B N$ được chẩn đoán gãy kín Dupuytren: Gãy xương mác ở vị trí $1 / 3$ dưới hoắc đâu dưới xương mác, có doãng mộng chày mác, bán trật khớp xương sên ra ngoài, có gãy mắt cá trong hoặc đứt dây chằng Delta. Tuổi tữ 18 tuổi trở lên, đã được kết xương bên trong. Hồ sơ bệnh án, phim X quang trước, sau mổ đầy đủ, rõ ràng.

Tiêu chuẩn loại trừ: Gãy xương bệnh lý, gãy xương ở chi sẵn có những dị tật, di chứng.

2.2. Phương pháp nghiên cứu: Mô tả cắt ngang. Cõ̃ mẫu thuận tiện.

Các chỉ tiêu nghiên cứu

- Các yếu tố dịch tễ: Tuổi, giới, vị trí, nguyên nhân, cơ chế chấn thương.

- Triệu chứng lâm sàng: đau vị trí ổ gãy, hạn chế vận động khớp cổ chân, mất vận động khớp cổ chẩn, xác định điểm đau chói, mức độ sưng nề cổ chân, tình trạng phỏng nước ở cổ bàn chân.

- Hình ánh $X$ quang:

+ Vị trí gãy các mắt cá (1 mắt cá, 2 mắt cá, 3 mắt cá), hình thái đường gãy.

+ Hình ảnh doãng mộng chày mác, trật khớp chày sên. Một số chỉ số giúp xác định tình trạng của khớp chày - mác dưới.

- Trên phim XQ cổ chân tư thế thẳng:

+ Khoảng sáng chày - mác. Bình thường, khe này nhỏ hơn $5 \mathrm{~mm}$, khi khe này $>5 \mathrm{~mm}$ là chỉ 
điểm của doãng mộng chày mác.

+ Khoảng chồng chày - mác . Bình thường $\geq$ $6 \mathrm{~mm}$ và bất thường nếu $<6 \mathrm{~mm}$.

Khớp chày - mác dưới được xem là bị tổn thương nếu có một trong hai giá trị này, hoặc cả hai số đo này bị bất thường.

Trên phim XQ cổ chân xoay tư thế xoay trong bàn chân $15^{\circ}$ (Mortise View).

+ Khoảng sáng khe khớp bên trong trên phim mortise (medial clear space). Bình thường $\leq 4 \mathrm{~mm}$, nếu $>4 \mathrm{~mm}$ được xem là doãng mộng chày mác.

+ Độ chồng chày - mác trên phim mortise: > $1 \mathrm{~mm}$ là bình thường, nếu hai xương không chồng lên nhau, gợi ý doãng mộng chày mác.

*Hình ảnh gãy mắt cá sau trên phim nghiêng.

*Hình ảnh gãy mắt cá sau trên Xquang thẳng: Dấu hiệu đường viền kép, hình núi mờ.

Hình ảnh CT scanner (nếu có): hình thái, kích thước mảnh gãy mắt cá sau, doãng mộng chày mác, từ đó phân loại gãy mắt cá sau theo Bartonicek [4].

Phân loại cơ chế chấn thương theo Lauge Hansen và phân loại gãy mắt cá theo Danis- Weber.

\section{KẾT QUẢ NGHIÊN CứU}

3.1. Đặc điểm dịch tễ: $22 \mathrm{BN}$ nam (57,9\%) và nữ có $16 \mathrm{BN}(42,1 \%)$. Tuổi trung bình 46.26 (22-72) tuổi. Nguyên nhân chủ yếu là TNGT (chiếm 56,2\%). TNSH: 13 BN (34,2\%), TNTT: 3 BN (7,9\%), TNLĐ: 2 BN (5,3\%). Bên phải bị chấn thương gặp 15/38 BN (39,5\%), bên trái bị chấn thương gặp 23/38 BN (60,5\%).

3.2. Đặc điểm lâm sàng: Đau, sưng nề, điểm đau chói cố định, bất lực vận động khớp cổ chân gặp ở 38/38 BN. Dấu hiệu phỏng nước gặp 2/38 BN (chiếm 5,2\%).

\section{3. Đặc điểm cận lâm sàng}

3.3.1. Vị trí mắt cá chân tổn thương: Gãy 3 mắt cá chân hay gặp nhất $(52,63 \%)$, sau đó là gãy 2 mắt cá $(44,74 \%)$, chỉ có $1 \mathrm{BN}$ chỉ gãy mắt cá ngoài.

3.3.2. Hình thái đường gãy.

Bảng 1. Hinh thái đường gãy xương $(n=38)$

\begin{tabular}{|c|c|c|c|}
\hline Hình thái đường gãy & $\begin{array}{c}\text { Gãy } \\
\text { MCT }\end{array}$ & $\begin{array}{c}\text { Gãy } \\
\text { MCN }\end{array}$ & $\begin{array}{c}\text { Gãy } \\
\text { MCS }\end{array}$ \\
\hline Gãy ngang & 32 & 4 & 0 \\
\hline Gãy chéo đơn thuân & 5 & 26 & 14 \\
\hline Gãy chéo có mảnh rời & 0 & 8 & 6 \\
\hline Tống & $\mathbf{3 7}$ & $\mathbf{3 8}$ & $\mathbf{2 0}$ \\
\hline
\end{tabular}

Nhận xét: Gãy MCT hay gặp đường gãy ngang (32/37 BN). Trái lại, gãy MCN thì gãy chéo hay gặp hơn (30/38 BN). Gãy MCS thì 20/20 BN $(100 \%)$ có đường gãy chéo trên XQ nghiêng.

Trên phim $X$ quang thẳng của $20 \mathrm{BN}$ có gãy mắt cá sau: 4/20 BN có dấu hiệu đường viền kép, 16/20 BN có dấu hiệu đường gãy phía sau.

3.3.3. Phân tích cơ chế chấn thương theo phân loại của Lauge - Hansen. $100 \%$ BN có cơ chế xoay ngoài, trong đó ngửa - xoay ngoài chiếm $65,8 \%$ và sấp - xoay ngoài chiếm $34,2 \%$. Không gặp cơ chế ngửa-khép, sấp-xoay ngoài, sấp- gấp cổ chân.

3.3.4. Phân loại gãy mắt cá theo Denis Weber. Loại B: $23 / 38$ BN (60,5\%), loại C: $15 / 38$ BN (chiếm 39,5\%)

3.3.5. Hình ảnh doãng mộng chày mác trên hình ảnh $X$ quang. Dựa vào hình ảnh $X$ quang tư thế thẳng xác định được $100 \%$ bệnh nhân đều có hình ảnh doãng mộng chày mác.

3.3.6. Hình ảnh bán trật khớp xương sên trên phim X quang. $100 \%$ BN có bán trật khớp xương sên trên phim Xquang thẳng, nghiểng. Có $18 / 38$ BN có bán trật khớp xương sên ra ngoài, 20/38 BN có xương sên vừa bán trật khớp ra ngoài và sau, do có gãy kèm MCS.

3.3.7. Hình ảnh trên phim chụp CTScanner. Có $16 / 20 \mathrm{BN}(80 \%)$ có gãy ba mắt cá chân được chỉ định chụp CT Scanner. Có 4/16 BN $(25 \%)$ có diện tích mảnh gãy MCS < $25 \%$ diện tích bề mặt khớp chày sên. 14/16 BN (75\%) có diện tích mảnh gãy MCS $\geq 25 \%$ diện tích bề mặt khớp chày sên. Có 2 BN có mảnh gãy rời của mắt cá sau kẹt vào khớp chày mác dưới. $100 \%$ BN đều có mảnh gãy sau ngoài.

Phân loai gãy mắt cá sau theo Bartonicek thấy: Loại I có $2 / 16$ BN (12,5\%), loại II có 8/16 BN (50\%), loại III: 4/16 BN (25\%), loại IV có 2/16 BN (12,5\%)

\section{BÀN LUÂ̂N}

4.1. Đăc điểm chung của nhóm nghiên cứu. Trong nghiên cứu có $22 \mathrm{BN}$ nam $(57,9 \%)$ và nữ có $16 \mathrm{BN}(42,1 \%)$. Nguyên nhân chủ yếu là TNGT (chiếm $56,2 \%$ ), trong đó chủ yếu là tai nạn xe máy. Kết quả của chúng tôi phù hợp với kết quả của Ma Ngọc Thành (2010), Đỗ Tuấn Anh (2016) [5], [6]. Kết quả nghiên cứu của Burwell và Charnley cho thấy tai nạn lao động và tai nạn thể thao là nguyên nhân hay gặp [1].

4.2. Bàn luận về đặc điểm lâm sàng và chẩn đoán hình ảnh

4.2.1. Bàn về đặc điểm lâm sang. Đau, bất lực vận động khớp cổ chân gặp ở 38/38 BN. Đau chói cố định là triệu trứng thực thể điển hình và dễ xác định trền lâm sàng do mắt cá chân nằm ngay dưới da.

Dấu hiệu phỏng nước rất có ý nghĩa trên lâm sàng. Nó quyết định đến thái độ xử trí và tiên 
lượng của bác sĩ. Chúng tôi chỉ gặp 2/38 BN (chiếm $5,2 \%$ ) có phổng nước. Chúng tôi không cố gắng tìm dấu hiệu lạo xạo xương mặc dù đây là dấu hiệu chắc chắn của gãy xương.

4.2.2. Đặc điểm chẩn đoán hình ảnh. Đặc điểm và hình thái của tổn thương: Tổn thương 3 mắt cá chân là hay gặp nhất (gặp ở 20/38 BN, chiếm $52,63 \%$ ). Tỷ lệ này cao hơn so với Burwell (13/135 BN), Ma Ngọc Thành (11/35 BN), Đỗ Tuấn Anh (16/55 BN) [1], [5], [6]. Do MCS là một phần phía sau của đâu dưới xương chày nên khi bị gãy đều có hình ảnh đường gãy chéo vát trên phim $X$ quang nghiêng. Trên phim $X$ quang cổ chân tư thế thẳng của 20 BN có gãy mắt cá sau thì có 4 bệnh nhân có hình đường viền kép, $16 \mathrm{BN}$ có hình núi mờ. Như vậy, hình ảnh XQ tư thế thẳng và nghiêng cho phép chẩn đoán được gãy mắt cá sau tuy nhiên không đánh giá được vị trí ở trong hay ngoài, hình thái mảnh gãy, diện tích mảnh gãy...

Gãy 2 mắt cá trong và ngoài cũng chiếm tỉ lệ cao với 17/38 BN (44,74\%). Một số tác giả thấy đây là tổn thương gay gặp nhất: Ma Ngọc Thành $(57,14 \%)$, Đố Tuấn Anh (56,4\%), Soohoo (45\%) [5], [6], [7].

Gãy một mắt cá chân chỉ gặp ở 1 BN gãy $\mathrm{MCN}$ ) $(2,63 \%)$, thấp hơn so với Soohoo (16\%) [7].

Gãy MCN thường gặp đường gãy chéo vát (30/38 BN), ngược lại MCT thì chủ yếu là gãy ngang (32/37 BN) do cơ chế chấn thương bàn chân xoay ngoài làm xương mác bị gãy gián tiếp, dây chằng Delta bị kéo căng. Kết quả này phù hợp với Ma Ngọc Thành (2010), Đố Tuấn Anh (2016) [5], [6].

Chúng tôi nhận thấy rằng để chẩn đoán gãy mắt cá chân đơn thuần thì chụp $X Q$ thường quy là đủ xác định. Tuy nhiên nếu có gãy MCS thì nên chụp CT sanner để xác định hình thái, kích thước mảnh gãy phía sau, phát hiện mảnh gãy nội khớp từ đó đưa ra đường mổ, phương pháp cố định thích hợp. Có 16/20 BN có gãy MCS được chụp CT scanner thì đều có mảnh gãy sau ngoài, $4 \mathrm{BN}$ có mảnh gãy rời kẹt khớp chày mác dưới mà không xác định được bằng $X Q$ thường. Những nghiên cứu gần đây khuyên nên chụp CT scanner khi có gãy mắt cá sau [4], [5], [6].

Trong nghiên cứu của chúng tôi đa số bệnh nhân phần mềm sưng nề nhiều, hơn nữa chỉ định phẫu thuật ngay tổn thương dây chằng cổ chân trong cấp cứu khi gãy Dupuytren chưa đặt ra nên chúng tôi không chỉ định chụp MRI khớp cổ chân để xác định tổn thương dây chằng.

Bàn luận về trật xương sên và doãng mộng chày mác. Có $18 / 38$ BN có trật xương sên ra ngoài. 20/38 $B N$ vừa trật ra ngoài vừa trật ra sau, do bị gãy cả mắt cá sau. Kết quả này phù hợp với Ma Ngọc Thành và Đỗ Tuấn Anh [5], [6]. Nếu xương sên bị lệch ra ngoài $1 \mathrm{~mm}$ thì diện tích chịu lực khớp chày sên chỉ còn $42 \%$,di lệch từ 1- $2 \mathrm{~mm}$ chỉ còn $14 \%$, từ $2-4 \mathrm{~mm}$ là $9 \%$ và từ $4-6 \mathrm{~cm}$ chỉ còn $3 \%$ [8]. Điều đó cho thấy giá trị của việc phát hiện và điều trị loại tổn thương này. Nếu có mảnh gãy mắt cá sau kẹt khớp chày mác dưới, thì khó nắn chỉnh hoàn hảo mộng chày mác. Điều đó cho thấy vai trò quan trọng của chụp CT Scanner khi có gãy mắt cá sau.

\section{KẾT LUẬN}

- Đặc điểm lâm sàng: Tuổi trung bình 46,26 tuổi (22-72), nam/nữ =57,9\%/42,1\%. Nguyên nhân phổ biến nhất là TNGT $(56,2 \%)$. Cơ chế chấn thương hay gặp là bàn chân xoay ngoài (33/38 BN= 87,7\%). Đau khớp cổ chân, có điểm đau chói cố định, bất lực vận động, sưng nề biến dạng khớp cổ chân gặp ở $100 \% \mathrm{BN}$, ngắn nửa trước bàn chân chiếm $52,6 \%$ và phỏng nước ở cổ bàn chân chỉ chiếm $5,2 \%$.

- Đăc điểm XQ và CT-Scanner: Hình ảnh XQ khớp cổ chân tư thế thẳng- nghiêng cho thấy các tổn thương xương khớp: Gãy 3 mắt cá gặp nhiều nhất $20 / 38$ BN $(52,63 \%)$, rồi đến gãy 2 mắt cá có $17 / 38 \mathrm{BN}(44,74 \%)$; gãy mắt cá ngoài đơn thuần có $1 / 38$ BN (2,63\%). Loại DenisWeber B gặp nhiêu nhất 23/38 BN (60,5\%), loại C gặp ở 15/38 BN (39,5\%). 100\% BN có hình ảnh doãng mộng chày mác và bán trật khớp xương sên ra ngoài.

Hình ảnh $X$ quang cổ chân thẳng (đường viền kép $(20 \%)$, núi mờ $(80 \%)$ ) và nghiêng (đường chéo vát $(100 \%)$ ) cho phép chẩn đoán gãy mắt sau, tuy nhiên, chưa đánh giá chính xác kích thước, hình thái, vị trí mảnh gãy mắt cá sau. Hình ảnh CT scanner ở 20 BN gãy mắt cá sau cho phép đánh giá chính xác vị trí, hình dạng và kích thước của mảnh gãy phía sau, phát hiện được mảnh xương chèn vào khớp chày mác dưới và tình trạng doãng rộng khớp chây mác dưới. Chúng tôi khuyến cáo nên chụp CT-Scanner khi có gãy mắt cá sau.

\section{TÀI LIẸU THAM KHẢO}

1. Burwell H.N. và Charnley A.D. (1965). The treatment of displaced fractures at the ankle by rigid internal fixation and early joint movement. J Bone Joint Surg $\mathrm{Br}, 47(4), 634-660$.

2. Verhage S. (2019), Management of the posterior malleolus in trimalleolar fractures. 179, Leiden University, the Netherlands. 
3. Karande V., Nikumbha V.P., Desai A. el all. (2017), "Study of surgical management of malleolar fractures of ankle in adults", Int J Orthop Sci, 3(3), 783-787.

4. Bartoniček J., Rammelt S., Tuček M. el all. (2015), "Posterior malleolar fractures of the ankle", Eur J Trauma Emerg Surg, 41(6), 587-600.

5. Ma Ngọc Thành (2010), Đánh giá kết quả phẫu thuật gãy kín mắt cá chân tại bệnh viện hữu nghi Việt Đức, Luân văn thạc sĩ y hooc đaji học y Hà Nội.

6. Đố Tuấn Anh (2016). Kết quả phẩu thuật gãy kín xương mắt cá chân ở người trưởng thành tại bệnh viện Hữu nghị Việt Đức. Luận văn thạc sĩ y học đại học y Hà Nối.

7. SooHoo N.F., Krenek L., Eagan M.J. et all (2009). "Complication Rates Following Open Reduction and Internal Fixation of Ankle Fractures". JBJS, 91(5), 1042-1049.

8. Samuel B. Adams., David. M. Tainter, Michel A. Taylor (2020) "'Malleolar Fractures and Soft Tissue Injuries of the Ankle'"', Skeletal Trauma, 6 Edition; Chapter 66: 2446- 2484.

\section{PHẪU THUÂT THU GỌN VÚ SỬ DỤNG VẠT MANG PHỨC HỢP QUÂNG NÚM VÚ TRỤC MẠCH NGỰC TRONG}

\section{Trần Thiết Sơn*, Trương Thế Duy*, Phạm Thị Việt Dung*, Tạ Thị Hồng Thúy*, Vũ Hồng Chiến** \\ INTERNAL THORACIC ARTERY AXIAL PATTERN FLAP CARRYING NIPPLE AREOLA COMPLEX}

\section{TÓM TẮT}

Bài báo nhằm đánh giá đặc điểm vạt mang phức hợp quầng núm vú của động mạch ngực trong và kết quả sử dụng vạt mang phưưc hợp quầng núm vú trục mach ngức trong trong phâuu thuât thu gon vú phì đai. Tiển hành trên 30 bệnh nhân với 60 vú phì đại được thu gọn bằng vat phức hợp quầng núm vú trục mạch ngực trong tại bệnh viện Xanh Pôn và bệnh viện Bạch Mai từ 01/2017 đến 06/2021. Mức đô phì đai nhiều, rất nhiều chiếm 45 vú $(70 \%)$ và khổng lồ 14 vú $(23,3 \%)$. Trên siêu âm doppler cầm tay: $100 \%$ động mạch ngực trong cho nhánh nuôi vào quâng núm vú từ các phía: trên $(11,67 \%)$, trên trong $(75 \%)$ và trong (13,33\%). 20 động mạch vú trong của 10 bệnh nhân được khảo sát trên phim MSCT, nhánh vào quầng núm vú chủ yếu thuộc KLS II, III, 95\% có đường kính mach trên $1,5 \mathrm{~mm}$. Vat phức hợp quầng núm vú truc mach ngực trong thiết kế dưới 3 dạng theo hướng vào quầng núm vú của trục mạch: $45 / 60$ (75\%) cuống trên trong, 7/60 (11,67\%) cuống trên, 8/60 (13,33\%) cuống trong. 45/60 (75\%) Vạt có tỷ lệ dài/rông > 2/1, lớn nhất tới 4,43/1. 100\% Quầng núm vú sống. 14/60 quầng núm vú $(23,3 \%)$ bị rối loạn cảm giác. Sau 3 tháng, 8/14 quầng núm vú rối loạn cảm giác được phục hồi. Tóm lại, động mạch ngực trong rât đáng tin cậy trong cấp máu quâng núm vú. Thu gọn vú sử dụng vạt mang phức hợp quâng núm vứ trục mạch ngực trong đảm bảo sức sống và di chuyển linh động quầng núm vú, có thể áp dụng cho mọi mức độ vú phì đại.

Tư' khóa: Phì đại tuyến vú, phức hợp quầng núm vú, vạt trục mạch ngực trong.

\section{SUMMARY \\ BREAST REDUCTION SURGERY USING THE}

*Trường Đại học Y Hà Nội

**Bênh viện Bach Mai

Chịu trách nhiệm chính: Trương Thế Duy,

Email: theduytruonghmu@gmail.com

Ngày nhan bài: 9/8/2021

Ngày phản biên khoa hoc: 30/8/2021

Ngày duyệt bài: 28/9/2021
This article aims to evaluate the characteristics of blood supply to the nipple areola complex of the internal thoracic artery and the effectiveness of using internal thoracic artery axial pattern flap carrying the nipple areola complex in hypertrophy breast reduction performed in 30 patients with 60 hypertrophic breasts at Saint Paul hospital and Bach Mai hospital from January 2017 to June 2021 . Hypertrophic breasts were operated on including 45 high/very high breasts $(70 \%)$ and 14 giant breasts $(23.3 \%)$. The vascular axis was determined by hand-held doppler ultrasound: $100 \%$ of the nipple areola complex was supplied by anterior intercostal branches of the internal thoracic artery from the sides: superior (11.67\%), superomedial (75\%) and medial (13.33\%). 20 internal thoracic arteries of 10 patients were analyzed on MSCT, the branches entering the nipple areola complex mainly passed through the second and third intercostal spaces. $95 \%$ of them had vessel diameters greater than $1.5 \mathrm{~mm} .45$ flaps (75\%) had length/width ratio $>2 / 1$, the largest up to $4.43 / 1$. $100 \%$ of the nipple areola complex are survival. Sensory disturbances occurred in 14/60 nipple areola complex $(23.3 \%)$. After 3 months, $8 / 14$ of these nipples were restored to normal sensation. In summary, the internal thoracic artery is reliable in the nipple areola complex blood supply. Hypertrophy breast reduction using the internal thoracic artery axial pattern flap carrying the nipple areola complex ensures vitality and mobility of the nipple areola complex and can be applied to all degrees of breast hypertrophy.

Keywords: Hypertrophy breast, nipple areola complex, internal thoracic artery axial flap

\section{I. ĐĂT VẤN ĐỀ}

Phì đại vú là tình trạng tăng thể tích bất thường do quá phát mô tuyến cùng thâm nhiễm tổ chức mõ̃, gây hậu quả biến dạng và sa trễ bầu vú, thay đổi vị trí của phức hợp quầng núm vú (QNV). Vú phì đại gây rối loạn về chức năng 